\title{
Pre-operative Neutrophil-to-Lymphocyte Ratio is Associated with Post-operative Opioid Requirements and Length of Stay after Thoracotomy
}

\author{
I Wayan Suranadi, Tjokorda Gde Agung Senapathi, Ayu Dilia Febriani Wisnawa, Christopher Ryalino* \\ Department of Anesthesiology and Intensive Care, Faculty of Medicine, Udayana University, Bali, Indonesia
}

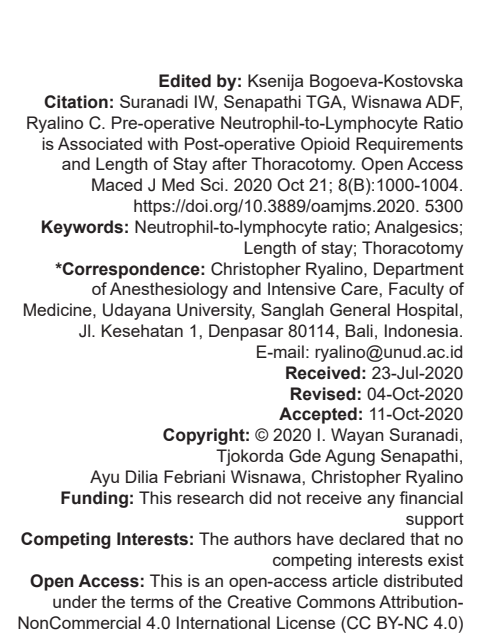

\begin{abstract}
BACKGROUND: Surgical pain and prolonged hospital length of stay (LOS) affect a large proportion of patients after thoracotomy. Inflammation plays a crucial role in the mechanism and progression of pain and the outcomes.

AIM: The objective of this study was to investigate the association between the pre-operative neutrophil-tolymphocyte ratio (NLR) and post-operative pain and LOS in patients undergoing thoracotomy.

METHODS: This was a retrospective, observational study on 157 patients who underwent thoracotomy under general anesthesia. We classified the subjects into two study groups: Group with for patients with NLR $<2$ and Group 2 for NLR $\geq 2$. We measured the post-operative pain by gathering the data of post-operative opioid needs. We used Pearson's and Spearman's correlation tests to assess the association of the parameters.

RESULTS: The mean of total oral morphine equivalent in the first $48 \mathrm{~h}$ following thoracotomy in Group 1 was $140.8 \pm$ $60.4 \mathrm{mg}$ compared to Group 2's $109.7 \pm 55.8(\mathrm{p}<0.05)$. The median hospital's LOS was longer in Group 2 compared to Group 1 ( 7 vs. 10, p < 0.001). We found a weak positive correlation between pre-operative NLR $(R=0.267$ $p=0.002$ ) and post-operative opioid requirements, and a weak positive correlation between pre-operative NLR and the hospital's LOS $(R=0.345, p<0.001)$.
\end{abstract}

CONCLUSION: Pre-operative NLR correlates with post-operative opioid requirements and the time hospital's LOS in patients who underwent elective thoracotomy.

\section{Introduction}

The need for surgery and anesthesia services is expected to continue to increase over the following decade to reduce the risk of death and disability [1]. Surgery has become an essential part of healthcare service, with an estimated 234 million surgical procedures performed each year and the number increasing annually [2]. The potential harm as a result of invasive procedures of surgery includes pain after surgery. Further, inadequate acute pain management may lead to significantly worsened morbidity and may contribute to the development of chronic postoperative pain syndrome that could ultimately result in mortality [3]. It has been estimated that post-operative pain syndrome affects $50 \%$ of patients following surgery [4]. Appropriate pain control leads to increased patient comfort, earlier mobilization time, decreased pulmonary and cardiac complication, faster recovery period, without disturbing complication, reduce the time of hospitalization, and therefore cost of care [4], [5].

Pain has been a concerning and focused research topic in thoracic surgery. The pain experienced in thoracotomy represents one of the most severe of all surgical procedures and considered to be severe as a consequence of tissue damage related to surgery that alters chest wall mechanics [6]. Inflammation stimulated by surgical injury, which includes incision, manipulation of ligaments and muscles, retractions of the ribs with compression, stretching of the intercostal nerves, possible rib fractures, and pleural irritation plays a key role in the mechanism, development, and progression to the severity of the post-operative pain and also prolonged hospital length of stay (LOS) [4]. Despite many strategies has been investigated, post-operative pain remains a significant problem, unresolved healthcare problem and continues to present a problem to clinicians. Therefore, well-planned pain control, including providing effective pain relief with appropriate and adequate analgesic regimen has been essential in decreasing morbidity after thoracotomy and improved surgical outcome [7], [8].

Determining predictive factors of surgical pain may help clinicians to allow adequate pain relief, including prescribes well-targeted analgesia and according to the patient's need. Recent studies revealed that the usage of appropriate pain control could improve 
better clinical outcomes, including pain management and hospital LOS [9]. Despite numerous studies of pain related to surgery have been done, less attention has been paid on the influence and association of preoperative immune system status to pain after surgery, especially in thoracotomy surgery.

To evaluate the immune system status of the patients, we used the neutrophil-to-lymphocyte ratio (NLR) that has been known as one of the most sensitive markers for diagnosis, treatment, and prognosis in a broad spectrum from many clinical conditions, including stratifying patients in term of inflammation status [10], [11]. In this study, we aimed to investigate and evaluate the relationship between pre-operative NLR and pain in thoracotomy.

\section{Materials and Methods}

We retrospectively identified medical and anesthesia medical records of 157 patients who underwent several different types of procedural approaches of thoracotomy under general anesthesia in our hospital between January 2017 and July 2019. We included patients aged $\geq 18$ years old with American Society of Anesthesiologists (ASA) physical status class I-III who underwent thoracotomy under general anesthesia during the timeframe. Exclusion criteria include incomplete medical records (i.e., missing preoperative neutrophil and lymphocyte data) and patients with malignancy. The study has been approved by the Committee of Ethical Research of Udayana University.

The demographic and clinical characteristics were recorded, including age, sex, body mass index (BMI), duration of surgery, pre-operative vital signs, and ASA physical status. The analgesics regiments used during the perioperative period and the LOS were collected. We also collected the data for pre-operative NLR and white blood cells count. In the course of this study, laboratory results dated from a month or less before the day of surgery were considered valid for reporting. NLR was calculated as absolute neutrophil count divided by absolute lymphocyte count.

Post-operative pain was assessed by total morphine consumption in the first $48 \mathrm{~h}$ after the surgery. For better comparison, cumulative opioid consumption at the first $48 \mathrm{~h}$ period was converted to their respective oral morphine equivalent daily dose (OMEDD) as per Australian and New Zealand College of Anaesthetists, as shown in Table 1 [12]. For the purpose of this study, patients with pre-operative NLR $\geq 2$ were classified as "high" and therefore carried inflammatory status. Patients with NLR $<2$ were classified as low NLR.

The characteristics of the subjects were presented either in proportional value, mean \pm standard
Table 1: Oral morphine equivalent conversion factor

\begin{tabular}{lll}
\hline Current opioid & Conversion factor & \\
\hline Oral (Swallowed) preparations & mg/day & \\
Morphine & $\mathrm{mg} /$ day & 1.5 \\
Oxycodone & $\mathrm{mg} / \mathrm{day}$ & 5 \\
Hydromorphone & $\mathrm{mg} / \mathrm{day}$ & 0.13 \\
Codeine & $\mathrm{mg} / \mathrm{day}$ & 0.2 \\
$\quad$ Tramadol & $\mathrm{mcg} / \mathrm{h}$ & \\
Transdermal preparations & & 3 \\
$\quad$ Fentanyl & $\mathrm{mg} / \mathrm{day}$ & \\
Parenteral preparations & $\mathrm{mg} / \mathrm{day}$ & 3 \\
$\quad$ Morphine & $\mathrm{mg} / \mathrm{day}$ & 3 \\
Oxycodone & $\mathrm{mg} / \mathrm{day}$ & 15 \\
Hydromorphone & $\mathrm{mg} / \mathrm{day}$ & 0.25 \\
Codeine & $\mathrm{mcg} / \mathrm{day}$ & 0.4 \\
Pethidine & $\mathrm{mcg} / \mathrm{day}$ & 0.2 \\
Fentanyl & & 2 \\
$\quad$ Sufentanil & & \\
\hline
\end{tabular}

deviation, or median with interquartile range. Normally distributed data were analyzed using the KolmogorovSmirnov test. Categorical data were compared by Chisquare $\left(\chi^{2}\right)$ test or Fisher's exact test. Independent t-test or Mann-Whitney U-test were used to determine the difference between variables. Parametric values were evaluated with the independent t-test, whereas non-parametric values were evaluated with the MannWhitney U test. Spearman's correlation was used to determine the correlation between variables when the data were not normally distributed, and Pearson's correlation was performed otherwise. All statistical analyses were performed using the Statistical Package for the Social Sciences (SPSS) software for windows version 22.0 (IBM Corp. Released 2013. IBM SPSS Statistics for Windows, Version 22.0. Armonk, NY: IBM Corp.). $\mathrm{p}<0.05$ was considered statistically significant.

\section{Results}

During the study period, medical records of 137 patients (82 males and 55 females) met the study (Table 2). The mean age of the patients was 46.3 years. There were no significant differences between age, weight, BMI, pre-operative blood pressure, preoperative respiratory rate, and premedication used between the high-NLR and low-NRL groups. The

Table 2: Baseline data and study parameters

\begin{tabular}{|c|c|c|c|}
\hline \multirow[t]{2}{*}{ Parameters } & Group $1(n=68)$ & Group $2(n=69)$ & \multirow[t]{2}{*}{$\mathrm{p}$-value } \\
\hline & NLR $<2$ & $\mathrm{NLR} \geq 2$ & \\
\hline Age (years), mean $\pm S D$ & $45.9 \pm 13.9$ & $46.6 \pm 13.6$ & $0.776^{\mathrm{a}}$ \\
\hline \multicolumn{4}{|l|}{$\operatorname{Sex}(n, \%)$} \\
\hline Male & $32(47.1)$ & $50(72.5)$ & \multirow[t]{2}{*}{$0.002^{c}$} \\
\hline Female & 36 (52.9) & $19(27.5)$ & \\
\hline Duration of surgery (h), median (IQR) & $2.3(0.7)$ & $2.4(0.7)$ & $0.195^{\mathrm{b}}$ \\
\hline Bodyweight (mean $\pm S D), \mathrm{kg}$ & $58.7 \pm 10.5$ & $61.3 \pm 12$ & $0.171^{\mathrm{a}}$ \\
\hline BMI (mean $\pm \mathrm{SD}$ ), $\mathrm{kg} / \mathrm{m}^{2}$ & $22.5 \pm 3.9$ & $22.7 \pm 3.9$ & $0.665^{\mathrm{a}}$ \\
\hline \multicolumn{4}{|l|}{ ASA physical status ( $n, \%)$} \\
\hline I & $5(7.4)$ & $1(1.4)$ & \multirow[t]{3}{*}{$0.011^{\mathrm{c} *}$} \\
\hline II & $34(5)$ & $2(22)$ & \\
\hline III & $29(42.6)$ & $46(66.7)$ & \\
\hline $\begin{array}{l}\text { Total oral morphine equivalent } \\
\text { required in the first } 48 \mathrm{~h} \text { after the } \\
\text { surgery }(\mathrm{mg}) \text {, mean } \pm \mathrm{SD}\end{array}$ & $109.7 \pm 55.8$ & $140.8 \pm 60.4$ & $0.002^{\mathrm{a}^{*}}$ \\
\hline LOS (days), median (IQR) & $7(4)$ & $10(5.5)$ & $<0.001^{\mathrm{b}^{\mathrm{t}}}$ \\
\hline
\end{tabular}


number of patients treated postoperatively with opioid in the high-NLR group was $51(75 \%)$ compared to 60 patients $(87 \%)$ in the low-NLR group.

The mean of total oral morphine equivalent in the first $48 \mathrm{~h}$ following thoracotomy in Group 2 was significantly higher than in Group 1 (140.8 \pm 60.4 vs. $109.7 \pm 55.8, p<0.05)$. Median hospital LOS of the patients was longer in Group 2 compared to Group 1 (7 vs. 10, $p<0.001$ ). We performed Pearson's correlation test between pre-operative NLR and postoperative opioid dose requirements. The result found a weak positive correlation between pre-operative NLR $(R=0.267, p=0.002)$. And then, we performed Spearman's correlation test between pre-operative NLR and the LOS. The result found a weak positive correlation between pre-operative NLR and the hospital's LOS $(R=0.345, p<0.001)$, as seen in Table 3.

Table 3: Correlation between NLR with total opioid consumption and LOS

\begin{tabular}{lll}
\hline Correlation to NLR & $\mathrm{r}$ & $\mathrm{p}$ \\
\hline Total opioid consumption in the first 48 h after the surgery & 0.267 & $0.002^{\mathrm{a}}$ \\
LOS at the hospital & 0.345 & $<0.001^{\mathrm{b}}$ \\
\hline${ }^{\text {a}}$ Pearson's correlation ${ }^{\mathrm{b}}$ Spearman's correlation. NLR. Neutrophil-lymphocyte ratio LOS. Length of stay
\end{tabular}

a Pearson's correlation ' 'S pearman's correlation. NLR: Neutrophil-lymphocyte ratio, LOS: Length of stay.

\section{Discussion}

We investigated the potential association between pre-operative NLR with post-operative pain and hospital LOS in patients who underwent thoracotomy in a single-center tertiary teaching hospital. To the best of our knowledge, this is the first study of its kind in patients who underwent a thoracotomy procedure.

The primary goal in the management of postoperative pain is providing adequate analgesia while still minimizing the dose of medication to lessen side effects to the patients. Our study found that opioid demand was higher in patients with a high NLR level than patients with low NLR levels at pre-operative [13]. Opioid are potent analgesics that have potential adverse effects and have been to be an effective way to improve pain management and quality of life. Moreover, this study found that the mean intraoperative opioid dose in patients with a high level of NLR was higher than in patients with a lower level of NLR. Our findings are in line with the previous study that patients who receive a high rather than a low intraoperative systemic opioid dose experienced more significant post-operative pain, despite an increased post-operative opioid consumption [14], [15], [16].

Our obtained results showed that higher preoperative inflammatory status which was evaluated by NLR of patients resulted in higher pain perception which was evaluated by analgesic demand and type of analgesic used in the first incision to $48 \mathrm{~h}$ following surgery, as a mean of total OMEDD in $48 \mathrm{~h}$ of thoracotomy was significantly higher in the Group 2 compared to Group 1. Our results also indicate that high NLR correlates with increased LOS. This result reveals that higher pre-operative inflammatory status of patients will increase analgesic consumption with higher potency of analgesic. Furthermore, a higher pre-operative inflammatory status will increase the LOS. In other words, patients with high pre-operative inflammatory status showed more analgesic demand that indicated a higher perception of pain level, and it had increased their LOS in the hospital. Patients with higher pre-operative NLR levels will have a higher analgesic requirement, especially for opioid usage. A previous study found that patients who chronically had opioid analgesics daily led to opioid-tolerant conditions that likely had higher health resource utilizer, and they had higher than expected time of hospitalization [17].

Major interest was directed toward the role of neutrophil and lymphocyte, which were formulated as NLR is an inflammation indicator. The recent study shows that NLR is a marker of subclinical inflammation and integrates detrimental effects of neutrophilia (an indicator of inflammation) and lymphopenia (an indicator physiological stress) and has emerged as a useful inflammatory marker or in combination with other biomarkers to determine and stratify patients in terms of inflammation [18], [19]. In general, a higher NLR is positively related to high mortality, poor prognosis, inflammatory status, and its consequences. It is well-known that NLR is a potential biological marker of inflammation in several diseases and can be a useful predictive tool for post-operative pain resulted from inflammatory pathways secondary to surgical trauma [20], [21], [22]. NLR is an easily calculated and inexpensive marker in daily clinical practice. NLR is derived from a routine complete blood count in the preoperative period without additional cost.

There is no established definite cutoff value for NLR in literature. Previous studies found an optimal cutoff ratio as an indicator of an inflammatory status ranges from 2 to 4 [23], [24], [25], [26]. In our study, we also used a cutoff point of NLR $\geq 2$, significantly associated with an inflammatory condition that is in line with prior results.

Turgut et al. [22] retrospectively evaluated the predictive role of pre-operative NLR and post-operative pain in 140 patients who underwent orthognathic surgery. They reported that the analgesic demand with NLR $\geq 2$ correlates with increased post-operative pain, which is consistent with the results of our study. Öner et al. [27] retrospectively evaluated pre-operative NLR and post-operative pain in 63 patients who underwent arthroscopic rotator cuff repair. The study summarized that pre-operative NLR was the most substantial factor predicting high acute pain levels.

On the other hand, Daoudia et al. [28] evaluated the predictive value of pain-related attitudes and the 
status of the immune system for the post-operative analgesic requirement in their study on 60 patients who underwent laparoscopic cholecystectomy under general anesthesia. They determined the association between NLR and total analgesic requirements during the first 48 $\mathrm{h}$ as the primary endpoint. They concluded that lower NLR correlates with higher analgesic requirements. Our study found, however, a positive association between higher NLR and pain-related surgery. The differences in methods used for evaluating analgesic requirements and population studied may lead to the contrary results between the two studies.

Our study found that pre-operative NLR was correlated with higher post-operative opioid requirements and increased LOS, but it was not designed to rule out the specific mechanism involved. In the state of inflammation, cytokines production may directly influence the NLR, in which inflammation is a base mechanism for transduction and transmission of pain stimuli [25]. Patients with higher NLR with enhanced pre-operative systemic inflammation maybe probably more exposed to the non-resolution of pain due to this altered inflammatory balance, as well as reflect an altered inflammatory balance within the central nervous system, in which inflammatory signaling is a major mechanism of hyperalgesia [29], [30]. Furthermore, pre-operative stratification to the patients according to basal inflammation might be useful to predict analgesics' effectiveness to prevent postoperative complications.

We can hypothesize that the patients with a pre-operative high inflammatory status could have more analgesic requirements and also more hospital LOS, but this remains speculative and should be tested in further studies. There are some limitations to our study. It has a relatively small sample size, and it is an observational and retrospective study. Furthermore, the post-operative pain was assessed solely by opioid requirements and not the pain score.

\section{Conclusion}

Pre-operative NLR correlates with postoperative opioid requirements and the time hospital's LOS in patients who underwent elective thoracotomy.

\section{References}

1. Meara JG, Leather AJ, Hagander L, Alkire BC, Alonso N Ameh EA, et al. Global surgery 2030: Evidence and solutions for achieving health, welfare, and economic development. Lancet. 2015;386(9993):569-624. https://doi.org/10.1016/j. surg.2015.02.009

PMid:25924834

2. Bhasin SK, Roy R, Agrawal S, Sharma R. An epidemiologica study of major surgical procedures in an Urban population of East Delhi. Indian J Surg. 2011;73(2):131-5. https://doi. org/10.1007/s12262-010-0198-x PMid:22468063

3. Endo I, Kumamoto T, Matsuyama R. Postoperative complications and mortality: Are they unavoidable? Ann Gastroenterol Surg. 2017;1(3):160-3. https://doi.org/10.1002/ags3.12045 PMid:29863116

4. Gerner P. Postthoracotomy pain management problems. Anesthesiol Clin. 2008;26(2):355-67.

PMid:18456219

5. Ramsay MA. Acute postoperative pain management. Proc (Bay Univ Med Cent). 2000;13(3):244-7.

PMid:16389390

6. Tukanova K, Papi E, Jamel S, Hanna GB, McGregor AH, Markar SR. Assessment of chest wall movement following thoracotomy: A systematic review. J Thorac Dis. 2020;12(3):1031-40. https://doi.org/10.21037/jtd.2019.12.93 PMid:32274172

7. Soto RG, FuES. Acute pain management for patients undergoing thoracotomy. Ann Thorac Surg. 2003;75(4):1349-57. PMid: 12683601

8. Luo J, Min S. Postoperative pain management in the postanesthesia care unit: An update. J Pain Res. 2017;10:268798. https://doi.org/10.2147/jpr.s142889

PMid:29180895

9. Gélinas C, Arbour C, Michaud C, Vaillant F, Desjardins S. Implementation of the critical-care pain observation tool on pain assessment/management nursing practices in an intensive care unit with nonverbal critically ill adults: A before and after study. Int J Nurs Stud. 2011;48(12):1495-504. https://doi.org/10.1016/j. ijnurstu.2011.03.012

PMid:21550048

10. Azab B, Zaher M, Weiserbs KF, Torbey E, Lacossiere K, Gaddam S, et al. Usefulness of neutrophil to lymphocyte ratio in predicting short- and long-term mortality after non-ST-elevation myocardial infarction. Am J Cardiol. 2010;106(4):470-6. https:// doi.org/10.1016/j.amjcard.2010.03.062

PMid:20691303

11. Howard R, Kanetsky PA, Egan KM. Exploring the prognostic value of the neutrophil-to-lymphocyte ratio in cancer. Sci Rep. 2019;9(1):19673. https://doi.org/10.1038/s41598-019-56218-z

12. Opioid Dose Equivalence-Calculation of Oral Morphine Equivalent Daily Dose (OMEDD); 2014. Available from: https://www.fpm. anzca.edu.au/documents/opioid-dose-equivalence.pdf.

13. Rasor J, Harris G. Opioid use for moderate to severe pain. J Am Osteopath Assoc. 2005;105(6 Suppl 3):S2-7.

PMid:16118359

14. Carroll IR, Angst MS, Clark JD. Management of perioperative pain in patients chronically consuming opioids. Reg Anesth Pain Med. 2004;29(6):576-91. https://doi.org/10.1016/j. rapm.2004.06.009 PMid:15635517

15. Chia YY. Intraoperative high dose fentanyl induces postoperative fentanyl tolerance. Can J Anaesth. 1999;46(9):872-7. PMid:10490157

16. Guignard B, Bossard AE, Coste C, Sessler DI, Lebrault C, Alfonsi $\mathrm{P}$, et al. Acute opioid tolerance: Intraoperative remifentanil increases postoperative pain and morphine requirement. Anesthesiology. 2000;93(2):409-17. https://doi. org/10.1097/00000542-200008000-00019 
PMid: 10910490

17. Gulur P, Williams L, Chaudhary S, Koury K, Jaff M. Opioid tolerance--a predictor of increased length of stay and higher readmission rates. Pain Physician. 2014;17(4):503-8.

PMid:25054400

18. Halazun HJ, Mergeche JL, Mallon KA, Connolly ES, Heyer EJ. Neutrophil-lymphocyte ratio as a predictor of cognitive dysfunction in carotid endarterectomy patients. J Vasc Surg. 2014;59(3):768-73. https://doi.org/10.1016/j.jvs.2013.08.095 PMid:24571940

19. Wang $X$, Zhang G, Jiang $X$, Zhu H, Lu Z, Xu L. Neutrophil to lymphocyte ratio in relation to risk of all-cause mortality and cardiovascular events among patients undergoing angiography or cardiac revascularization: A meta-analysis of observational studies. Atherosclerosis. 2014;234(1):206-13. https://doi. org/10.1016/j.atherosclerosis.2014.03.003

PMid:24681815

20. Bhat T, Bhat H, Raza M, Khoueiry G, Meghani M, Akhtar M. Neutrophil to lymphocyte ratio and cardiovascular diseases: A review. Expert Rev Cardiovasc Ther. 2013;11(1):55-9. https:// doi.org/10.1586/erc. 12.159

PMid:23259445

21. Ozbay I, Kahraman C, Balikci HH, Kucur C, Kahraman NK, Ozkaya DP, et al. Neutrophil-to-lymphocyte ratio in patients with peripheral vertigo: A prospective controlled clinical study. Am J Otolaryngol. 2014;35(6):699-702. https://doi.org/10.1016/j. amjoto.2014.08.004

PMid:25219290

22. Turgut $H$, Alkan $M$, Ataç $M$, Altundağ $S$, Bozkaya $S$, Şimşek $B$, et al. Neutrophil lymphocyte ratio predicts postoperative pain after orthognathic surgery. Niger J Clin Pract. 2017;20(10):12425. https://doi.org/10.4103/1119-3077.181399 PMid:29192626

23. Bugada D, Lavand'homme P, Ambrosoli AL, Cappelleri G, Saccani Jotti GM, Meschi T, et al. Effect of preoperative inflammatory status and comorbidities on pain resolution and persistent postsurgical pain after inguinal hernia repair. Mediators Inflamm. 2016;2016:5830347. https://doi. org/10.1155/2016/5830347

PMid:27051077
24. Hong J, Mao Y, Chen X, Zhu L, He J, Chen W, et al. Elevated preoperative neutrophil-to-lymphocyte ratio predicts poor disease-free survival in Chinese women with breast cancer. Tumour Biol. 2016;37(3):4135-42. https://doi.org/10.1007/ s13277-015-4233-1 PMid:26490984

25. Qin B, Ma N, Tang Q, Wei T, Yang M, Fu H, et al. Neutrophi to lymphocyte ratio (NLR) and platelet to lymphocyte ratio (PLR) were useful markers in assessment of inflammatory response and disease activity in SLE patients. Mod Rheumatol. 2016;26(3):3726. https://doi.org/10.3109/14397595.2015.1091136 PMid:26403379

26. Jung MR, Park YK, Jeong O, Seon JW, Ryu SY, Kim DY, et al Elevated preoperative neutrophil to lymphocyte ratio predicts poor survival following resection in late stage gastric cancer. J Surg Oncol. 2011;104(5):504-10. https://doi.org/10.1002/ jso.21986 PMid:21618251

27. Öner K, Okutan AE, Ayas MS, Paksoy AE, Polat F. Predicting postoperative pain with neutrophil/ lymphocyte ratio after arthroscopic rotator cuff repair. Asia Pac J Sports Med Arthrosc Rehabil Technol. 2020;20:24-7. https://doi.org/10.1016/j. asmart.2020.03.001

PMid:32211297

28. Daoudia M, Decruynaere C, Le Polain de Waroux B, Thonnard JL, Plaghki L, Forget P. Biological inflammatory markers mediate the effect of preoperative pain-related behaviours on postoperative analgesics requirements. BMC Anesthesiol. 2015;15(1):183. https://doi.org/10.1186/s12871-015-0167-9 PMid:26674471

29. Hains LE, Loram LC, Weiseler JL, Frank MG, Bloss EB, Sholar $\mathrm{P}$, et al. Pain intensity and duration can be enhanced by prior challenge: Initial evidence suggestive of a role of microglial priming. J Pain. 2010;11(10):1004-14. https://doi.org/10.1016/j. jpain.2010.01.271

PMid:20434956

30. Burian M, Geisslinger G. COX-dependent mechanisms involved in the antinociceptive action of NSAIDs at central and peripheral sites. Pharmacol Ther. 2005;107(2):139-54. https:// doi.org/10.1016/j.pharmthera.2005.02.004

PMid:15993252 